\title{
Infância Calin: Socialização Étnica e Identidade Social entre Crianças Ciganas
}

\author{
Grecy Kelle Andrade Cardoso ${ }^{1}$ \\ ${ }^{1}$ Universidade Federal do Espírito Santo, ES, Brasil.
}

\author{
Mariana Bonomo ${ }^{2}$ \\ ${ }^{2}$ Universidade Federal do Espírito Santo, ES, Brasil.
}

Resumo: Compreendendo fases sucessivas do momento de proteção, aprendizagem e preparação para se tornarem adultas, na infância, as crianças ciganas vão sendo formadas para uma vida em grupo e voltada para o núcleo familiar. A partir dos conceitos de socialização étnica e de identidade social, o estudo foi desenvolvido com o objetivo de analisar o universo psicossocial da infância calin entre crianças de etnia calon no estado do Espírito Santo. Participaram do estudo sete crianças, com idades entre 4 e 12 anos, que compõem a terceira geração da comunidade, a primeira após processo de fixação territorial. As entrevistas foram orientadas por um roteiro semiestruturado explorando os universos da lei cigana, tradições do grupo e vivências cotidianas, bem como técnicas de desenho a fim de conhecer as imagens de si, da família e de futuro. Todas as entrevistas foram realizadas no acampamento cigano e os dados foram analisados por meio da análise de conteúdo temática. Os principais resultados demonstraram que as crianças calin destacam em suas narrativas a vivência da lei cigana e das tradições por meio do uso de vestimentas típicas e da língua caló, moradia em tendas e obediência às normas para o matrimônio, bem como relatam rotinas envolvendo brincadeiras, escolarização e atividades de mediação para o universo adulto. Nesse contexto, manifestam-se movimentos de resistência do grupo, em que a nova geração teria como tarefa manter os elementos identitários essenciais da cultura cigana e criar recursos para manutenção de sua sociabilidade em trânsito nas fronteiras com o mundo não cigano.

Palavras-chave: Ciganos, Infância, Identidade Social, Socialização Étnica.

\section{Calin Childhood: Ethnic Socialization and Social Identity Among Gypsy Children}

\begin{abstract}
Comprising successive phases of the moment of protection, learning and preparation to become adults, gypsy children are being raised for a life in group and geared towards the family nucleus. Based on the concepts of ethnic socialization and social identity, the study was developed in order to analyze the psychosocial universe of Calin childhood among Calon children in the State of Espírito Santo. Seven children aged between 4 and 12 years participated in the study. They make up the third generation of the community, the first one after the process of territorial settlement. The interviews were guided by a semi-structured script exploring the universes of Gypsy law, group traditions and everyday experiences, as well as drawing techniques in order to know the images of oneself, the family and the future. All the interviews were carried out in the Gypsy camp and the data were analyzed through the thematic content analysis approach. The main results showed that Calin children emphasize in their narratives the experience of Gypsy law and traditions through the use of typical dress and Caló language, residence in tents and obedience to norms for marriage, as well as routines involving games, schooling and mediation activities for the adult universe. In this scenario, the resistance movements of the group rise, in which the new generation will have to protect the essential identity elements of the Gypsy culture and create resources to maintain their sociability in transit on the borders with the non-Gypsy world.
\end{abstract}

Keywords: Gypsies, Childhood, Social Identity, Ethnic Socialization. 


\title{
Infancia Calín: Socialización Étnica e Identidad Social entre Niños Gitanos
}

\begin{abstract}
Resumen: En la infancia, los niños gitanos se van formando para una vida en grupo y orientada hacia el núcleo familiar, comprendiendo fases sucesivas del momento de protección, aprendizaje y preparación para hacerse adultos, en la infancia. A partir de los conceptos de socialización étnica y de identidad social, el estudio fue desarrollado con el objetivo de analizar el universo psicosocial de la infancia calin entre niños de etnia calon en el estado de Espírito Santo. Participaron del estudio 7 niños, entre 04 y 12 años de edad, que componen la tercera generación de la comunidad, la primera después del proceso de fijación territorial. Las entrevistas fueron orientadas por un guion semiestructurado explorando los universos de la ley gitana, tradiciones del grupo y vivencias cotidianas, así como técnicas de dibujo a fin de conocer las imágenes de sí, de la familia y del futuro. Todas las entrevistas se realizaron en el campamento gitano y los datos fueron analizados por medio del análisis de contenido temático. Los principales resultados demostraron que los niños calin destacan en sus narrativas la vivencia de la ley gitana y de las tradiciones por medio del uso de ropas típicas y de la lengua caló, vivienda en tiendas y obediencia a las normas para el matrimonio, así como también relatan rutinas que involucran juegos, escolarización y actividades de mediación para el universo adulto. En este contexto, se manifiestan movimientos de resistencia del grupo, en el que la nueva generación tendría como tarea mantener los elementos identitarios esenciales de la cultura gitana y crear recursos para mantener su sociabilidad en tránsito en las fronteras con el mundo no gitano.
\end{abstract}

Palabras clave: Gitanos, Infancia, Identidad Social, Socialización Étnica.

\section{Introdução}

As contribuições da Psicologia para o debate e reflexão sobre a promoção dos direitos dos povos e comunidades tradicionais em território nacional têm se identificado, marcando o compromisso social da área em defesa da diversidade de modos de vida que compõem as sociabilidades e formas de existência no Brasil contemporâneo. Apesar de avanços em sua inserção nos diferentes campos de atuação junto às minorias sociais (Botomé, 2010; Machado, \& Calais, 2018), é possível observar que, em relação a inúmeros grupos sociais, essa tarefa parece constituir-se ainda em momento de descobertas e provocações à área $p s i$; questão que parece aplicar-se à realidade dos povos ciganos no contexto brasileiro (Bonomo, Souza, Livramento, Brasil, \& Sousa, 2018; Costa, 2015; Dias, 2016; Silva, 2006).

A produção de conhecimento sobre os ciganos no Brasil ainda é escassa (Ferrari, \& Frotta, 2014), assim como são poucas as políticas públicas de garantia de direitos a essa população (por exemplo: Lima, 2014; Moonen, 2013; Secretaria de Políticas de Promoção da Igualdade Racial - Seppir, 2013a;b). Apesar dos desafios envolvidos no desenvolvimento de pesquisas com os ciganos (por exemplo: Condon et al., 2019; Durst, \& Nyírő, 2018; Messing, 2019), entender como os grupos étnicos ciganos valorizam e lutam pela manutenção de suas identidades nos modos de vida contemporâneos apresenta-se como tarefa de grande relevância (Cittadini, 2018; Heaslip, \& Smith, 2016; Simões, 2014), tendo em vista a necessidade de contribuir para a visibilidade e o reconhecimento social dessa minoria, pouco conhecida, mas que há séculos vive sob a sombra do preconceito e da discriminação social, no Brasil e em vários contextos geográficos do mundo (por exemplo: Acton, 2018; Hutchison, Chihade, \& Puiu, 2018; Kende, Hadaricsa, \& Lášticováb, 2017; Law, \& Kovats, 2018; Lima, 2014; Lima, Faro, \& Santos, 2016; Miškolci, Kováčová,, \& Rigová, 2018; Moonen, 2012; 2013; Powell, 2008; Powell, \& Lever, 2017; Tremlett, 2017; Villano, Fontanella, Fontanella, \& Donato, 2017; Wallace, Townsend, \& Salemink, 2018).

Nessa perspectiva, o presente estudo tem por objetivo analisar, no contexto da infância cigana, os processos identitários e de socialização étnica entre crianças de etnia calon de um acampamento no estado do Espírito Santo, tendo como eixo de reflexão que integra a perspectiva de análise empreendida a 
abordagem sociocultural dos processos de desenvolvimento identitário do tornar-se cigano(a).

Entendendo os referidos processos de desenvolvimento a partir de uma perspectiva psicossocial, que reconhece a interdependência do indivíduo à sua cultura de pertença, conforme pressupostos defendidos e aprofundados nas abordagens da Psicologia Cultural, a cultura como mundo social seria a portadora de sentido da existência humana. Nas interações sociais e encontro com a diversidade de modos de vida, os indivíduos são desafiados tanto cognitiva quanto afetivamente, produzindo narrativas sobre si e seu contexto. Esse processo envolve a esfera da linguagem e comunicação, bem como sistemas de crenças, valores sociais e semântica afetiva no trabalho de construção da vida cotidiana e de um universo familiar aos indivíduos e grupos sociais (Anoli, 2004; Emiliani, 2008).

Nos grupos étnicos que são genericamente denominados de ciganos, os ciclos de vida não são delimitados apenas por fases etárias (Bonomo et al., 2018; Monteiro, \& Goldfarb, 2017). A infância para os ciganos compreende, portanto, fases sucessivas do momento de proteção, de aprendizagem e de preparação para tornar-se adulto (Monteiro, \& Goldfarb, 2017). Entre os calon, por exemplo, a infância se estende até o matrimônio, momento em que a menina e o menino se tornarão homem e mulher perante a sua família e comunidade, e iniciarão uma nova unidade familiar (Bonomo et al., 2018; Monteiro, \& Goldfarb, 2017; Montini, 2018; Pizzinato, 2009). Nessa concepção, as crianças vão sendo preparadas para viver em uma comunidade em que eles serão, acima de tudo, membros de um grupo familiar (Lalueza, \& Crespo, 2009).

Entende-se a infância cigana, portanto, como antecedente ao casamento, ou seja, o casamento é o rito essencial para compreender as etapas geracionais entre diversos grupos ciganos, e ocorre através de regras específicas, que são, geralmente, muito valorizadas pelo grupo, sendo relacionado à comunidade como um todo e não apenas ao casal (Montini, 2017; Monteiro, \& Goldfarb, 2017; Ozkan, 2006). O matrimônio, portanto, se torna uma questão sociocultural de destaque, que ganha relevância desde cedo por meio do ritual de acordos entre as famílias e que se refletem nas promessas de casamento entre os filhos (Pizzinato, 2009).

A vivência dos ciganos em grupos e comunidades tradicionais desde o nascimento pode reproduzir nas crianças mecanismos de defesa e de afetos, fun- damentados e adaptados nas condições e necessidades da vida naquele grupo (Berthier, 1979; Montenegro, 2013; Poveda, \& Marcos, 2005). As brincadeiras, que comumente já fazem parte do universo infantil, também são importantes no processo de socialização da criança cigana (Azevedo, \& Cardoso, 2012), assim como o conjunto de regras que são a elas transmitidas a fim de garantir a perpetuação das normas e das tradições do grupo (Bonomo et al., 2018; Bonomo, Souza, Brasil, Livramento, \& Canal, 2010; Pizzinato, 2009). Nessa perspectiva, os pais preparam os filhos, capacitando-os para as tarefas que serão desempenhadas no grupo futuramente, o que coloca as crianças ciganas em uma posição central para o futuro do grupo, em um contexto em que elas podem também representar a esperança de continuidade da tradição nas próximas gerações (Berthier, 1979; Pinto, 2017; Pizzinato, 2009; Rodriguez, 2011; Simões, 2014).

\section{Socialização étnica e identidade social entre os ciganos}

A partir dos conceitos de socialização étnica e de identidade social, o presente estudo foi desenvolvido tendo por objetivo analisar, no contexto da infância cigana, os processos identitários e de socialização entre crianças de etnia calon de um acampamento no estado do Espírito Santo.

Entende-se por identidade étnica, nesse estudo, o pertencimento a um grupo social étnico, cujos processos identitários compreendem a vivência de diferentes práticas sociais do grupo e categoria social, mediadores da inserção dos indivíduos na vida social e na cultura de referência (Carvalho, 2005; Hogg, Abrams \& Brewer, 2017). Como dimensão da identidade social dos indivíduos, essa pertença está associada ao sentir-se parte do grupo e ao reconhecer-se ligado à categoria social, envolvendo critérios internos (com aspectos cognitivos, avaliativos e emocionais) e externos (de reconhecimento) para uma identificação grupal. De acordo com Tajfel (1983), seria “aquela parcela do autoconceito de um indivíduo que deriva do conhecimento da sua pertença a um grupo (ou grupos) social, juntamente com o significado emocional e de valor associado àquela pertença" (p. 290). Ou seja, a identidade social está ligada ao reconhecimento da pertença aos grupos sociais, bem como ao significado emocional e de valor atribuídos a esse pertencimento.

Como processo de elaboração da identidade social no contexto do pertencimento a um grupo 
étnico, a análise empreendida nesse estudo apoia-se na ideia de socialização a partir da intersecção dos diferentes agentes socializadores na atuação integrada do grupo cigano sobre a formação dos indivíduos. A socialização, portanto, é um processo no qual os indivíduos apreendem e interiorizam padrões, valores e normas culturais inerentes ao contexto social de pertença (Demartis, 1999, Elkin, 1968), o que implica na transmissão dos valores e da cultura passados por diferentes gerações (Pinheiro, 2012). Nesse contexto, os grupos sociais e os ambientes com os quais o indivíduo interage ao longo da sua vida funcionam como agentes de socialização (Elkin, 1968) ou "instâncias socializadoras" (Grigorowitschs, 2008). Logo, a socialização permeia a vida das pessoas, assumindo um papel decisivo nos modos de interpretar e de agir no mundo social (Abrantes, 2011; Elkin, 1968; França, 2013).

A percepção de pertença a determinado grupo étnico, sobretudo quando essa identidade étnica está associada a representações negativas, depende das concepções construídas tanto pelos membros do grupo quanto das demais sociabilidades (Magano, 2010; 2017). As práticas de socialização nesses contextos étnico-culturais podem variar de acordo com o reconhecimento identitário e características dos pais e das crianças, também podendo aumentar conforme a idade (Hughes et al., 2006; Nelson, Syed, Tran, Hu \& Lee, 2018). Todavia, tanto as crianças de grupos minoritários quanto dos grupos majoritários, desde cedo, atribuem aspectos positivos ao próprio grupo (Alexandre, Monteiro \& Waldzus, 2007; Bigazzi, \& Csertő, 2016; Dimitrova \& Ferrer-Wreder, 2017). A esse respeito, Pnevmatikos, Geka e Divane (2010) informam, por exemplo, que desde os quatro anos de idade as crianças já conseguem distinguir os membros do seu próprio grupo étnico de pessoas de outros grupos, com base em aspectos culturais comuns, bem como já conseguem verbalizar (desde os cinco anos de idade) preferências endogrupais e expressar afetos negativos em relação aos grupos étnicos minoritários (Nesdale, 2001).

Crianças pertencentes a grupos étnicos minoritários (como os grupos ciganos), no entanto, podem crescer na dicotomia entre a cultura vivida pelos seus pais e a cultura hegemônica do país no qual estão localizados, ou seja, podem viver e serem escolarizadas entre dois contextos etnico-culturais distintos (Carvalho, 2005). Consequentemente, a socialização entre dois grupos diferentes e com status desiguais (majoritário e minoritário) pode levar à identificação com um ou ambos os grupos, podendo ainda interferir no processo de afirmação identitária (Hogg, Abrams \& Brewer, 2017).

A inserção da criança cigana no ambiente escolar, por outro lado, é descrita como um possível momento de choque cultural e de vivência de preconceitos (Azevedo, \& Cardoso, 2012; Rosário et al., 2017; Silva, \& Paiva, 2015). Logo, ainda na atualidade, muitos pais ciganos relutam para enviar seus filhos ao ambiente escolar não cigano, por medo de assimilação e de exposição dos filhos a situações de discriminação (Casa-Nova, 2005; Čvorović, 2005; Levinson, 2005; 2008; Robinson, \& Martin, 2008; Rosário et al., 2017; Simões, 2010; Zachos, \& Panagiotidou, 2019).

As experiências coletivas de infância e as trocas intergeracionais (Abrantes, 2011; Tomizaki, 2010) são conceitos relevantes para o entendimento de como adultos e crianças vão construindo experiências, pertenças e disposições ao longo desse processo de socialização. No contexto de socialização étnica, a família (especialmente os pais) age ativamente como relevantes agentes para a formação da identidade de seus filhos (Čvorović, 2005; Dimitrova, Ferrer-Wreder, \& Trost, 2015), exercendo função educativa e integradora (Montenegro, 2003), de modo que a educação familiar cigana configura-se não apenas como instrumento de transmissão de normas e valores, mas, também, como elemento cultural chave no processo de construção social da identidade cigana (Paiva, 2013; Souza, Bonomo, Livramento, Brasil, \& Canal, 2009). Destaca-se, no entanto, que, quanto maior for a transmissão étnica durante o processo de socialização, maior será a identificação, a preferência e os sentimentos positivos para com o próprio grupo étnico (Dimitrova, \& Ferrer-Wreder, 2017; Dimitrova, Johnson, \& Van de Vijver, 2018; França, 2013), bem como índices de satisfação com a vida mais elevados (Abubakar, \& Dimitrova, 2016; Dimitrova, Ferrer-Wreder, \& Trost, 2015; Dimitrova et al., 2018; Hughes et al., 2006).

O ser cigano(a), portanto, estaria relacionado às experiências e socializações que os indivíduos adquirem em seu próprio contexto étnico-grupal, aos valores morais (como respeito, honra e vergonha), às tradições e aos costumes que se expressam mediante aos rituais de passagem estabelecidos e vivenciados nos grupos (Castro, 2011; Garrido, 1999; Magano, 2010; 
Paiva, 2013), uma vez que os encontros e as trocas do grupo se tornam pilares para a coesão e a identidade grupal (Batista, 2001; Hogg et al., 2017).

\section{Método}

Com delineamento qualitativo, de característica descritiva e exploratória, nesse estudo, considerou-se os princípios de articulação de diferentes técnicas, segundo proposição da triangulação metodológica, que tem a função de promover indicadores de validade e qualidade, garantindo que tanto os resultados quanto as interpretações sejam confiáveis e multidimensionais (Flick, 2009; Ollalk, \& Ziller, 2012). Nessa perspectiva, no presente trabalho, utilizou-se diversos recursos, tais como entrevista individual, desenhos infantis e registros em diário de campo, visando abordar diferentes dimensões do fenômeno em análise.

\section{Caracterização dos participantes}

O estudo foi desenvolvido com a participação de todas as crianças da terceira geração de um grupo cigano, cujo acampamento localizava-se em área periférica de um centro urbano no estado do Espírito Santo. Dessa forma, no total, sete crianças (quatro meninos e três meninas), com idades entre $4 \mathrm{e}$ 12 anos, filhos e filhas de ciganos de étnica calon e de mães gadjés (mulheres não ciganas casadas com ciganos), participaram da pesquisa.

Na Tabela 1, são apresentados os nomes fictícios (escolhidos pelos próprios participantes), suas idades e informações relacionadas à escolarização. Essas crianças são a primeira geração do grupo em processo de fixação territorial ou seminomadismo local, e que nunca realizaram viagens para além dos bairros vizinhos.

\section{Instrumentos}

Como instrumentos para coleta dos dados, foram utilizados os seguintes recursos: i) Ficha de identificação dos participantes, contendo questões relativas a dados socioeconômicos; ii) Roteiro semiestruturado de entrevista, abordando unidades de significação referentes às tradições e sistema normativo do grupo, à vivência da ciganidade e a atividades cotidianas; e iii) Roteiro para técnica de desenhos com inquérito posterior, abordando as imagens de si (da própria criança), da família cigana e de futuro (apenas três crianças quiseram participar dessa etapa). Como forma de se fornecer informações sobre o contexto do estudo, utilizou-se ainda a estratégia de registros em diário de campo.

\section{Procedimentos de coleta dos dados}

A partir da anuência do líder do grupo para inserção em campo e desenvolvimento do estudo, foram fornecidas todas as informações sobre os objetivos e questões éticas pertinentes ao desenvolvimento da pesquisa, a fim de se obter a devida autorização das crianças e de seus responsáveis. Dessa forma, em linguagem apropriada e acessível, os Termos de Assentimento foram lidos e explicados aos participantes, que forneceram sua autorização mediante registro verbal, gravada nos primeiros minutos dos áudios das entrevistas.

Tendo em vista a necessidade de adequação da linguagem, as entrevistas foram realizadas em formato de "bate-papo", nas próprias barracas ciganas e demais espaços do acampamento, com duração média de 50 minutos. Cabe mencionar, ainda, que a pesquisa foi aprovada pelo Comitê de Ética em Pesquisa, com código de registro CAAE: 76459417.8.0000.5542.

Tabela 1

Caracterização das crianças calin, participantes do estudo.

\begin{tabular}{lccc}
\hline Nomes fictícios & Idade & Está estudando? & Nível de escolarização \\
\hline Mateus & 12 anos & Sim & $5^{\circ}$ ano \\
Gabriela & 11 anos & Não & $5^{\circ}$ ano \\
Daniel & 10 anos & Sim & $3^{\circ}$ ano \\
Milena & 8 anos & Sim & $2^{\circ}$ ano \\
Tiago & 6 anos & Sim & Creche \\
Ana & 4 anos & Não & - \\
Lucas & 4 anos & Não & - \\
\hline
\end{tabular}




\section{Procedimentos de análise dos dados}

Tendo em vista a natureza dos recursos utilizados para coleta dos dados, envolvendo conteúdo textual e imagens (desenhos elaborados pelas crianças), todo material foi digitalizado para fins de tratamento e análise das informações obtidas por meio das entrevistas. Na sequência, a partir da técnica da análise de conteúdo categorial-temática, foram elaboradas categorias e subcategorias temáticas, submetidas a dois juízes independentes para fins de verificação de sua pertinência e validade.

A estratégia metodológica da análise de conteúdo consiste em um conjunto de recursos de análises baseadas na interpretação fundamentada em inferências (Castro, Abs, \& Sarriera, 2011). No modelo proposto por Bardin (1977/2010), esse método é definido como conjunto de regras lógicas de organização, categorização e tratamentos de dados (qualitativos ou quantitativos), através de recorte, agregação e enumeração. Tal método de análise visa, portanto, a sistematização e a descrição do conteúdo da mensagem, fornecendo indicadores quantitativos e qualitativos das comunicações (Bardin, 1977/2010; Oliveira, 2008).

No que se refere aos desenhos, é importante ressaltar que estes foram analisados através da produção discursiva das crianças sobre eles, uma vez que a ênfase não estava apenas na análise interpretativa das produções gráficas das crianças, mas, principalmente, em compreendê-las a partir de suas próprias verbalizações. Assim como Natividade, Coutinho e Zanella (2008), compreende-se o desenho infantil como forma de linguagem, com relevante papel tanto no desenvolvimento cognitivo quanto na criatividade e expressão das emoções para as crianças. Por meio do desenho, a criança objetiva seu pensamento e sua emoção, a partir de suas próprias interpretações sobre sua produção. Dessa forma, foi possível um aprofundamento das entrevistas com as crianças, por meio da utilização da técnica de desenhos, a fim de compreender os processos psicológicos envolvidos através de uma linguagem adequada ao público infantil.

\section{Resultados}

Os resultados são apresentados a partir de duas seções principais, voltadas para a (i) contextualização do território, a partir dos registros realizados em diário de campo; e (ii) descrição das unidades de signi- ficação produzidas a partir das narrativas das crianças sobre seu cotidiano e outras temáticas abordadas nas entrevistas.

\section{Contextualização do acampamento cigano}

De acordo com relatos dos adultos da comunidade, com o crescente processo de urbanização, diversos grupos ciganos com tradição de nomadismo foram se fixando em terremos baldios nos arredores de grandes centros urbanos da região, processo que provocou inúmeras mudanças na vida dos ciganos. Há, pelo menos, quatro décadas, o grupo deu início ao processo de fixação territorial, realizando deslocamentos apenas entre bairros locais e cidades capixabas vizinhas.

O tempo das tropas de mula foi ficando nas memórias das primeiras gerações, que recordam com saudade histórias marcadas pelos sentimentos de alegria e de liberdade; mas também retratam esse período como sendo caracterizado pelo enfrentamento de muitas dificuldades - como fome, cansaço, doenças causadas pela extrema exposição ao sol e à chuva, além do preconceito de moradores das regiões em que acampavam com as suas caravanas.

No momento em que a pesquisa de campo foi realizada, o acampamento cigano era formado por três subnúcleos familiares, interligados a partir de diferentes relações de parentesco. Nesse período, o grupo era composto por 21 pessoas de três diferentes gerações, sendo a primeira formada por oito pessoas (quatro homens e quatro mulheres), todos de origem calon, que vivenciaram o tempo de nomadismo entre os estados da federação vizinhos (Minas Gerais, Rio de Janeiro e Bahia). A partir da segunda geração (composta por três casais), os homens ciganos passaram a se casar também com as gadjin (mulheres não ciganas), evento que possibilitou a inserção de novos elementos à dinâmica da comunidade. Desse modo, as sete crianças que compõem a terceira geração do grupo (quatro meninos e três meninas), participantes desse estudo, são filhos e filhas de pais ciganos e de mães gadjin.

Sobre a composição do acampamento, parece ser importante destacar que existem diferenças econômicas entre as famílias, e, consequentemente, diferenças na configuração das barracas e dos pertences de cada grupo familiar (no momento da coleta dos dados, havia seis barracas no acampamento). Algumas famílias, por exemplo, possuíam móveis, eletrodomésticos, eletrônicos e carro; já outras não possuíam nem cama, 
ou possuíam apenas uma cama e um fogão de lenha improvisado. Todavia, apesar de condições econômicas diferenciadas, todos os integrantes do grupo afirmavam a preferência de viverem acampados juntos, incluindo aqueles que possuíam terrenos próprios e aqueles que já tiveram experiências de morar em casas.

\section{Universo das crianças calin: sonhos e vivências cotidianas}

Por meio da análise temática, identificou-se seis categorias principais, que reúnem campos de significação referentes a diferentes dimensões do cotidiano e da vida das crianças calin, conforme sistematizado na Tabela 2.

Na temática que retrata a "vivência da infância" pelas crianças no acampamento cigano, duas dimensões se destacam: o universo lúdico, com rotina em que se prevê tempo livre para brincadeiras de diferentes tipos, bem como atividades de formação das crianças para tarefas que irão assumir como principais responsáveis na vida adulta. Como explicam, as brincadeiras integram as crianças do acampamento, no espaço protegido do terreiro livre de terra, que tradicionalmente é construindo pela composição das barracas ao redor.

De noitão, a gente tem que dormir para ir na escola de manhã, mas de dia a gente brinca todo mundo junto. Assim que eu chego da escola, a gente brinca. Aí a gente brinca um tempão, um tempão mesmo junto, aí só quando dá à noite, só quando fica escuro, escuro mesmo, aí é hora de dormir, aí, cada um vai para sua barraca (Milena).

Ao mesmo tempo, também demarcaram que nesse período ocorre a preparação para a vida adulta, principalmente as meninas, que aprendem o cuidado com a barraca: "Desde os sete anos eu aprendi e ajudo. Eu lavo vasilha quando minha mãe sai, faço café. Mas brinco, minha mãe deixa eu ir brincar sim" (Gabriela).

Na temática sobre a "escolarização", as crianças apontaram a valorização da alfabetização ("Eu gosto, não quero parar não" - Mateus), bem como as dificuldades tanto na aprendizagem quanto no uso do uniforme ("a gente aprende a ler, a gente aprende continhas, que a gente tem muita dificuldades" - "Equando a gente bota aquele short, parece que a gente tá sem roupa. Eu me sinto muito estranha, parece que a gente tá sem roupa na escola" - Gabriela).

A inserção no ambiente escolar é apontada com estranhamento inicial ("Quando eu entrei na escola, já aconteceu de todo mundo ficar olhando pra gente e encarando pra gente... eu fiquei quieta no meu canto. Fiquei com muita vergonha e sozinha, até arranjar amigas, foi muito ruim" - Gabriela), mas que também surge como lugar de afirmação ("Eu falo que sou cigana na escola” - Milena). Outra questão a ser des-

Tabela 2

Categorias e subcategorias temáticas.

\begin{tabular}{|c|c|c|}
\hline $\begin{array}{l}\text { Categorias } \\
\text { Temáticas }\end{array}$ & Descrição da categoria & Subcategorias temáticas / conteúdo temático \\
\hline $\begin{array}{l}\text { Vivência da } \\
\text { infância }\end{array}$ & $\begin{array}{l}\text { Reúne conteúdos referentes ao } \\
\text { cotidiano das crianças calin. }\end{array}$ & Brincadeiras e atividades na barraca. \\
\hline Escolarização & $\begin{array}{c}\text { Aborda o processo de escolarização das } \\
\text { crianças calin. }\end{array}$ & $\begin{array}{l}\text { Valorização da alfabetização, dificuldades } \\
\text { na aprendizagem, uso do uniforme escolar, } \\
\text { estranhamento com os outros alunos não ciganos, } \\
\text { afirmação identitária e uso de segundos nomes. }\end{array}$ \\
\hline $\begin{array}{l}\text { Tecnologias e } \\
\text { Internet }\end{array}$ & $\begin{array}{l}\text { Retrata os dilemas do uso de novas } \\
\text { tecnologias entre as crianças calin. }\end{array}$ & $\begin{array}{l}\text { Usos e vantagens da internet, e opiniões dos pais } \\
\text { e avós. }\end{array}$ \\
\hline Leis cigana & Refere-se ao sistema normativo do grupo. & Regras sobre como se relacionar no grupo. \\
\hline Tradição cigana & $\begin{array}{l}\text { Consiste nas diferentes dimensões } \\
\text { da vivência da ciganidade a serem } \\
\text { aprendidas pelas crianças calin. }\end{array}$ & $\begin{array}{l}\text { Uso da língua caló, vestimentas ciganas, moradia } \\
\text { dos ciganos e casamentos. }\end{array}$ \\
\hline Ser cigano(a) & $\begin{array}{l}\text { Trata das concepções de ciganidade } \\
\text { apresentadas pelas crianças calin. }\end{array}$ & $\begin{array}{l}\text { Afirmação identitária, família cigana, possuir } \\
\text { “sangue cigano”, herança paterna, afeto positivo } \\
\text { pelo grupo e diferenciação dos não ciganos. }\end{array}$ \\
\hline
\end{tabular}


taca em relação ao ambiente escolar é que algumas crianças enfatizam que não falam seus nomes nesses espaços, usando segundos nomes em ambientes não ciganos ou em situações em que não se sentem seguras ('Meu nome na escola é outro... aí lá todo mundo me conhece só pelo nome que chamam na chamada" - Gabriela).

Na categoria 'tecnologias e internet' são agrupados os relatos dos usos e vantagens do acesso à internet, computador e celular pelas crianças, que utilizam esses recursos para conversar com os amigos nas redes sociais, realizar pesquisas e obter informações sobre determinado assunto, assim como para entretenimento dentro da barraca. As crianças também descrevem as opiniões dos pais e avós sobre o tema, tido como polêmico, segundo elas:

Minha mãe fica encrencando, achando que a gente tá jogando o jogo da baleia azul... ela viu falando na televisão, mas eu só jogo os jogos mesmo. Eles não entendem, aí fica achando que é coisa ruim internet, mas é bom (Mateus).

Ah, minha filha, eles odeiam... Eles não acham legal não, eles falam que é coisa ruim. Minha vó acha que facebook estraga a gente, mas eu acho que eles não gostam por causa de que a gente não dá muita atenção para eles e só fica no telefone... Mas não é sempre ruim, não! Tem os lados bom também de ter internet (Gabriela).

O sistema normativo ou as "leis ciganas" diz respeito às normas de comportamentos que regulam a relação entre pessoas e famílias do grupo. Nos relacionamentos conjugais, por exemplo, "tem regra de não brigar um com outro entre os ciganos” (Gabriela). Ao mesmo tempo, algumas tradições (tais como a barraca, os dentes de ouro e o nomadismo) foram apontadas como tradições do grupo, mas que as crianças já as viam com concepções diferentes, destacando que era possível continuar a ser cigano(a) mesmo sem elas - "Nem quem faz casa, mora em casa ou fica vestindo roupa sem ser de cigano, ainda é cigano" (Gabriela).

Como vivência da tradição cigana, na subcategoria "vestimentas ciganas", são agrupadas as tradições que, para as crianças, deveriam ser mantidas, como as roupas por gostos pessoais ("Eu gosto bem colorido. Eu gosto de muita cor, fita” - Gabriela), para não envergonhar o grupo ("Eles falam 'nossa senhora que vergonha!' Porque gente que não é cigana veste muita roupa pequena, mostrando tudo assim" - Gabriela), ou para não ser confundido com os não ciganos ("às vezes, quando a gente vai passear, aí eu coloco os vestidos de cigana, porque senão eles vai pensar que eu sou gadjin" - Milena).

Em relação ao casamento, as crianças explicam as regras de namoro ("Mas mesmo noivo, não pode ainda se beijar ainda, assim, não. Não pode se beijar antes, não. Cigana pura, só fica conversando de longe" - Gabriela) e as expectativas de quando irão se casar ("casar novinha que não é bom casar. Acho que 16 anos é a melhor idade" - Milena).

No subtema "moradia", são agrupadas narrativas daqueles que defendem a moradia em barracas ("É meio fresco, né. A gente acostuma, né, acostuma né... eu nasci assim. O bom que tem muito espaço" Mateus), os que afirmam o desejo pela casa ("Casa, porque é mais quente. Não dá aquelas poeiras, não faz a gente, ficar passando mal" - Milena) e ainda aqueles que transitam, manifestando a valorização das duas formas de habitação ("Eu faço uma casa e, quando eu quiser, eu mudo com a barraca. Ai, quando eu quiser, eu vou para lá na barraca também" - Daniel).

Sobre a relevância e manutenção da linguagem própria do grupo, a subcategoria "a língua caló" é destacada como herança e tradição do grupo, sendo usada também como forma de se proteger dos não ciganos: "Tem que falar caló, a gente aprende para conversar no meio dos gadjon" (Daniel); "No meio dos ciganos, tem que falar a língua. É porque, assim, a língua é dos ciganos... aí, às vezes, a gente quer contar um segredo da gente, aí a gente conta na língua" (Mateus). Além disso, segundo as crianças, o caló é aprendido ao observar os pais e avós: "Eu sempre vi da boca do meu avô, do meu pai. Aí eu fiquei sabendo também. Eu presto atenção em tudo o que eles falam para eu poder aprender também" (Gabriela).

Ao investigar os aspectos da identidade cigana, as crianças calin trazem conteúdos de autoafirmação da ciganidade, que foram agrupados na categoria "ser cigano(a)". As justificativas e explicações de ser cigano(a) para as crianças baseiam-se em diferentes dimensões, tais como: a) família cigana - "minha família é cigana, mãe ensinou eu e minha irmã ser assim. Agora vou ter um irmão cigano também, minha mãe tá grávida de um menino e ele vai nascer cigano como a gente" (Milena); b) possuir sangue cigano - "já nasceu com sangue de cigano já. $\mathrm{O}$ importante é nascer 
com sangue de cigano" (Gabriela); c) herança biológica paterna - "meu pai é todo cigano. Minha mãe é gadjin, mas como meu pai é todo cigano, eu também sou toda cigana também. Se meu pai é cigano e eu sou também" (Ana); d) afeto positivo pelo grupo - "eu gosto de ser cigano" (Daniel); e) diferenciação com os não ciganos - "nós não é gadjin" (Ana); e f) tradições - "eu gosto de ser cigano, é a tradição. Eu acho a tradição bonita da família. Os povo cigano é as tradição deles" (Mateus).

Reunindo conteúdos referentes à elaboração de imagens de si, da família e de futuro, por meio da construção de desenhos, três crianças se dispuseram a participar dessa etapa do estudo, conforme apresentado na Figura.

Observando os desenhos elaborados, é possível verificar que: i) Gabriela se desenhou sozinha, sorrindo, com um longo vestido cigano, com os cabelos soltos e uma coroa de princesa; ii) Daniel se desenhou sozinho, vestindo calças, botas e uma camisa simples.
Não quis desenhar chão ou céu. Durante o inquérito, ele projetou o desenho como sendo de outro menino cigano, com idade próxima a dele, e mencionou que o menino gostava de brincar, mas tinha de ir para a escola; iii) Já Milena se desenhou com um longo vestido rosa, cheio de babadinhos e franjas de fitas, e com os cabelos amarrados, em formato de rabo de cavalo.

Nessa primeira fase dos desenhos, as vestimentas e acessórios foram um fator de destaque nas produções das meninas. Gabriela explica: "Eu só faço mulher com vestido, não faço com essas roupa aí, não". Já Milena, que mencionou não gostar de usar vestidos de cigana, e que neste dia estava usando roupas não ciganas, quando foi solicitado que ela se desenhasse, Milena se representou com um vestido cheio de detalhes e adereços característicos da cultura cigana. E mesmo Daniel, que estava mais preocupado com as brincadeiras e a escola, por sua vez, também não deixou de destacar que, pelas roupas, era possível saber que o menino desenhado era um cigano: "Ele

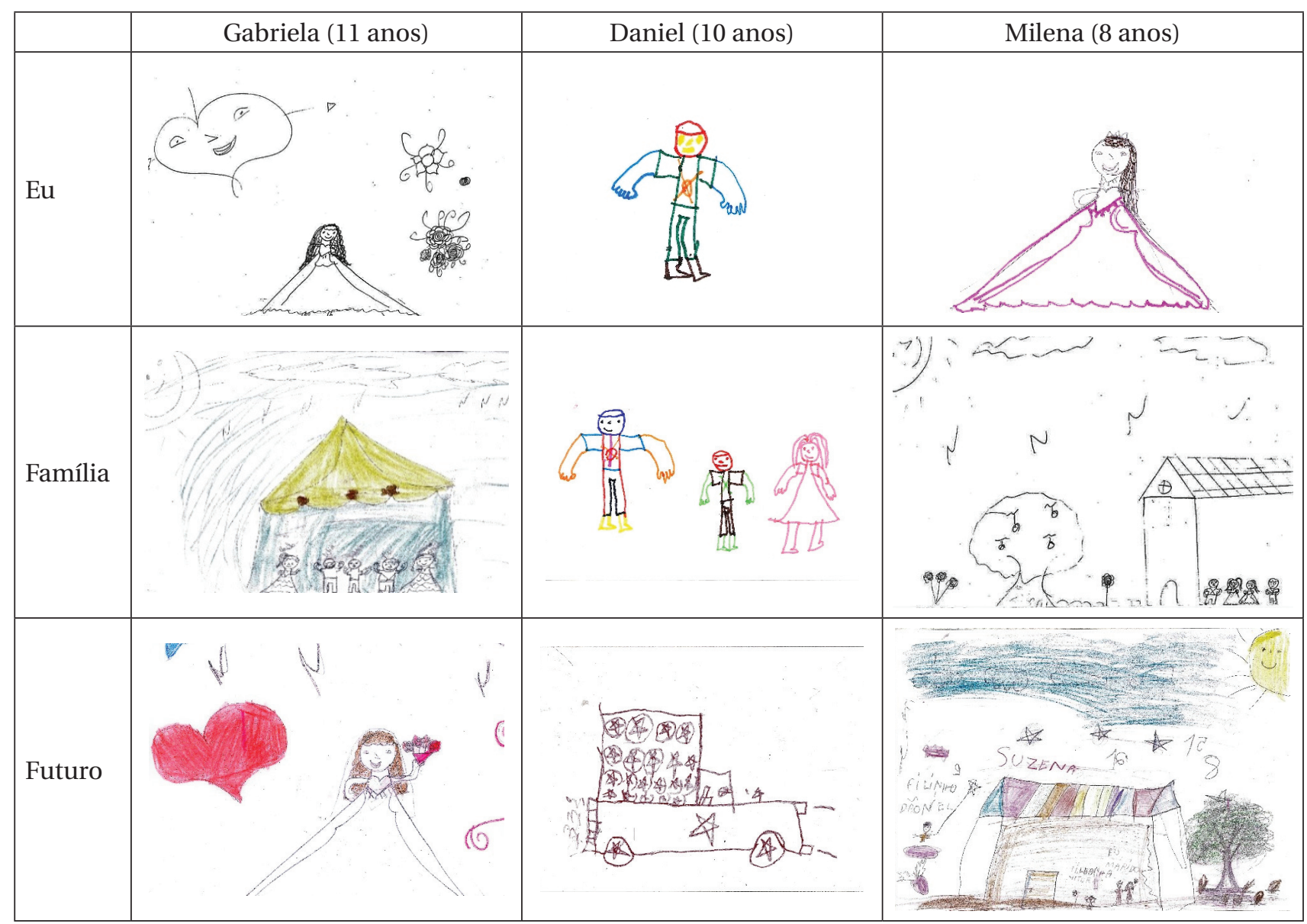

Figura.

Desenhos produzidos pelas crianças calin. 
brinca muito, o dia inteiro. Ele tem 11 anos. Ele gosta de estudar. Durante o dia ele brinca, mas a mãe dele fala pra ele ir na escola e ele para de brincar. Olha, ele tem uma bota e roupa de cigano".

Na segunda tarefa para as produções ilustrativas, foi solicitado que as crianças desenhassem uma família cigana: i) Gabriela desenhou sua família (pai, mãe, ela e os dois irmãos), todos estavam juntos no interior de uma barraca, colorida e enfeitada; ii) Daniel desenhou apenas ele e os pais, não incluiu os irmãos; e iii) Milena desenhou sua família, pai, mãe, ela e a irmã, bem como disse que também tinha outra na barriga da mãe (que estava grávida).

Nos desenhos das meninas, destaca-se a moradia, visto que no desenho de Gabriela o principal elemento foi a barraca (único item que foi colorido), enquanto, no desenho de Milena, ela destaca que a família está numa "casa-galpão", rica em detalhes e decorações no quintal (com flores e árvores): "É casa, mas não tem parede não. É que cigano mora em casa-galpão, fica tudo mundo junto lá dentro" (Milena). Destaca-se que apesar da família de Milena nunca ter morado em casas (segundo relato tanto da menina quanto dos seus pais), ainda assim, ela se ilustrava em uma casa-galpão, representando seu desejo acerca de como ela gostaria que fosse a moradia da família.

Além disso, também é possível perceber que todos os participantes se desenharam iguais aos seus pais, ou seja, as meninas se desenharam com detalhes que se assemelham às mães (Gabriela, por exemplo, se desenhou e desenhou a mãe com vestidos ciganos e em proporção maior que o pai e os irmãos), e o menino também se desenhou muito parecido com o pai, mudando apenas as cores das roupas e o tamanho, mantendo até a posição dos braços.

Quando questionadas sobre como seria a família cigana, a resposta das crianças apoia-se na ideia de uma família cigana desejada, grande e que todos morariam em um mesmo local (seja na casa-galpão ou na barraca). Nesse sentido, Gabriela também destaca que na família cigana se inclui os avós, mesmo que eles tenham sua própria barraca: "Família cigana é unida. É grande, tem que ter muita gente, pelo menos umas 7 ou 8 pessoas" (Gabriela).

Por fim, a última etapa consistiu em desenhar-se no futuro ("desenhe você no futuro"): i) Gabriela desenhou-se em um vestido de noiva e com buquê de flores nas mãos. E diferentemente da coroa de princesa do primeiro desenho, desta vez, ela se ilus- trou com vestido e véu de noiva; ii) o menino Daniel desenhou um carro com bastante equipamento de som automotivo, e disse que no futuro teria o próprio carro. Quando perguntado se ele também tinha o desejo de se casar, ele disse que um dia se casaria, mas que não sabia quando, pois gostaria de ter as coisas dele primeiro, e que iria trabalhar vendendo carros, sendo o seu próprio carro o "mais bonito e com sonzão"; já iii) Milena foi logo desenhando uma barraca bem colorida, com detalhes de flores, árvores, sol e nuvens, e também se desenhou casada ao lado do marido ("eu, marido, filhinho e outro filhinho do lado de fora da barraca"). Além disso, se representou com 15 anos e o marido com 16 anos.

Destaca-se que quando solicitada a projeção de futuro, ambas as meninas relacionam sua vida futura ao casamento, à constituição de uma família, com barraca própria e filhos. Cabe destacar que, no momento em que a coleta dos desenhos foi aplicada, nenhum dos participantes era prometido ou tinha acordos matrimoniais já estabelecidos. Gabriela até chega a enfatizar que, no seu desenho, ela tinha desenhado a noiva sem o noivo, pois ainda não o conhecia. Por outro lado, o menino destaca que a conquista de bens materiais e seguir a profissão do pai e avô (vendem carros) é como ele se imagina no futuro, no entanto não deixa de mencionar que provavelmente também se casaria futuramente.

Outra questão referente ao casamento reflete a temporalidade do quando se casar, que, na cultura cigana, marca a passagem da infância para a vida adulta. Eis o debate entre as crianças: "Tenho uma amiga que vai casar com 13 anos, mas eu quero casar com 15 e meu marido com 16" (Milena); "Eu não, eu quero com 18" (Gabriela); "Essas menina só pensa nesses papo de mulherzinha" (Daniel); "Você não entende nada porque é homem, eu sei, eu faço café, cozinho, sei ler e escrever, já ajudo na barraca da minha vó" (Gabriela).

Após todos finalizarem seus desenhos, em um momento coletivo do inquérito, outras questões sobre o que é preciso fazer e aprender para ser cigano(a) também surgiram, destacando a prática de negociação (barganha para o homem) e o domínio da língua caló: "Cigano compra e vende, esse é o trabalho de cigano” (Gabriela); “Tem que falar caló, a gente aprende para conversar no meio dos gadjon" (Daniel).

No que se refere à questão da moradia (morar em barraca ou casa), houve opiniões diferentes, por 
exemplo: "Alguns ciganos moram em casas e acham que é rico, esquece que são ciganos. Mas tem como ser cigano morando em casa ou barraca, tanto faz, nós não somos apegado nisso não" (Daniel); "Na barraca faz muito frio" (Milena); "Eu também preferiria a casa, mas tem que ser casa bem grande galpão, assim, a gente não gosta de parede não, casa de cigano é galpão" (Gabriela).

Por meio das produções pictográficas das três crianças que se dispuseram a participar dessa etapa do estudo, foi possível observar questões que se referem à ciganidade na infância, à valorização da família e às projeções de futuro. Ainda foi possível perceber que essas crianças também compreendem a infância como período até o casamento, com papéis sociais esperados e desejados pelo grupo, pelos pais e por elas próprias.

\section{Discussão}

A noção da infância como fase de preparo para a vida adulta, conforme resultados apresentados, orienta-se pela aprendizagem e valorização de aspectos culturais relacionados ao matrimônio, à constituição familiar e aos papéis e responsabilidades da vida adulta no grupo cigano, sendo geralmente diferenciados em relação ao gênero (por exemplo: Bonomo et al., 2018; Monteiro, \& Goldfarb, 2017; Montini, 2017; Pizzinato, 2009). A identidade cigana, portanto, pode ser entendida como processo, construído nesse contexto de socialização étnica (Dimitrova et al., 2018; Elkin, 1968; França, 2013; Pnevmatikos et al., 2010), que possibilita a aprendizagem, a valorização e a apreensão de valores, normas e crenças, entre outras características que são mantidas pelo grupo, por serem recursos identitários considerados essenciais à sua sociabilidade (Bigazzi, \& Csertő, 2016; Bonomo et al., 2018; Čvorović, 2005; Hogg et al., 2017).

A ciganidade, como expressão identitária, se materializa como um sentir-se cigano(a). Todavia, cabe destacar que não é apenas a unidade familiar que exerce essa socialização nas crianças do grupo (por exemplo: Carvalho, 2005; Hughes et al., 2006; Nelson et al., 2018), mas, é, sobretudo, com todo o grupo que elas aprendem a ser ciganas (Bonomo et al., 2018; Monteiro, \& Goldfarb, 2017; Montenegro, 2013; Pizzinato, 2009). Assim, a língua, as leis, as tradições e o modo de moradia (em tendas ou barracas) são afirmados como elementos culturais basilares ao grupo, ao mesmo tempo em que são debatidas possibilida- des de transformação para os próximos anos e gerações (Simões, 2014). Ou seja, segundo as próprias crianças, algumas dessas características podem ou não ser atualizadas sem perder aquilo que, para elas, representaria a ciganidade (Montenegro, 2013; Moonen, 2012; Paiva, 2013; Rodriguez, 2011).

Nesse sentido, dentre o leque de mudanças advindas na atualidade, o casamento e os papéis sociais esperados e desejados para a vida adulta ainda são almejados pelas crianças como perspectivas para o futuro (por exemplo: Bonomo et al., 2018; Simões, 2014), mas, concomitantemente, outros aspectos e novidades observadas por elas em sua geração, como por exemplo, a escolarização formal e o acesso à internet, também foram enfatizadas. E apesar de não ser possível prever como essas novas influências socializadoras poderão perpetuar na organização e nas próximas gerações do grupo (Simões, 2014), é relevante destacar que, ao se construir uma identidade social, as crianças ciganas poderão valorizar sua pertença e se esforçar para transmitir as características (por elas valorizadas) às próximas gerações, garantindo a manutenção da cultura cigana (Dimitrova, \& Ferrer-Wreder, 2017; Dimitrova et al., 2018; Pnevmatikos et al., 2010; Tomizaki, 2010).

Embora existam dilemas e medos relacionados a essa maior inserção das crianças em outros contextos sociais não ciganos (por exemplo: Abubakar, \& Dimitrova, 2016; Bigazzi, \& Csertő, 2016; Levinson, 2005; 2008; Rosário et al., 2017; Silva, \& Paiva, 2015; Simões, 2010; Zachos, \& Panagiotidou, 2019), os participantes desse estudo, juntamente com os seus pais e todo o seu grupo, atribuem forte conotação de valor positivo a algumas mudanças presentes na geração atual. Essa reflexão se aplica especialmente ao acesso à escolarização formal, tendo em vista a necessidade de se adaptarem às novas exigências sociais, bem como a expectativa de que um maior nível de escolarização pelas crianças seja utilizado para fortalecer a ciganidade, visando possíveis benefícios para todo o grupo cigano (Rosário et al., 2017; Zachos, \& Panagiotidou, 2019).

As crianças calin descrevem a ciganidade a partir tanto da herança biológica ("sangue cigano", linguagem paterna e familiar) quanto cultural, e que contribui para a diferenciação dos não ciganos. Desde cedo as crianças vão aprendendo a diferenciar ciganos e não ciganos, o que destaca a importância de fortalecer o orgulho de ser cigano(a) nas crianças, para assim 
construir e promover sua autoconfiança, autoestima e identidade (por exemplo: Dimitrova, \& Ferrer-Wreder, 2017; Dimitrova et al., 2015; 2018; Hughes et al., 2006).

A construção de uma identidade étnica também pode permitir o desenvolvimento de habilidades relacionadas a reconhecer e a lidar com a discriminação social, uma vez que a socialização étnica é descrita como possibilidade de fortalecimento da resistência dos jovens face à discriminação (Hughes et al., 2006). A esse respeito, a forma como as crianças ciganas compreendem o que é $\operatorname{ser}$ cigano(a) nas sociabilidades contemporâneas também é relevante para o entendimento dos seus direitos e o fortalecimento das suas estratégias de resistências frente às discriminações sociais, sobretudo, porque os diversos grupos étnicos ciganos presentes no Brasil ainda lutam pelo reconhecimento de suas identidades e estilos de vida (Lima, 2014; Moonen, 2013). Essa realidade social é semelhante em diversos grupos ciganos presentes em diferentes contextos geográficos do mundo, que possuem sua história e vida social marcadas por práticas de anticiganismo e exclusão (por exemplo: Moonen, 2012; 2013; Powell, \& Lever, 2017; Villano et al., 2017).

Apesar da grande invisibilidade social, do preconceito e da discriminação acerca dos ciganos, a ciganidade expressa pelas crianças calin, no presente estudo, como uma identidade positiva, envolve, simultaneamente, o desejo de continuidade desse modo de ser e a flexibilidade para atualização dos modos de viver a ciganidade. Evidencia-se, assim, que aprender a ser cigano estaria relacionado a saber manejar fronteiras (Montenegro, 2013; Paiva, 2013); ou seja, ser cigano(a) nas sociabilidades contemporâneas seria assumir uma ciganidade renovada, permeável a aprendizagem dos não ciganos, mas, também reflexiva sobre sua própria cultura, sendo inclusive capaz de suportar a inclusão de novas práticas para a manutenção da sua tradição (Montenegro, 2013; Pinto, 2017; Rodriguez, 2011).

As estratégias de resistência da cultura cigana, manifestas pelas crianças calin, seriam estratégias de adaptação tanto das condições de sociabilidades e tradições dos ciganos quanto da inserção social nas sociabilidades não ciganas (Montenegro, 2013; Simões, 2014). Nesse contexto, manifestam-se movimentos de resistência do grupo cigano, em que a nova geração teria como tarefa manter os elementos identitários essenciais da cultura cigana e criar recursos para manutenção de sua sociabilidade contemporânea, em trânsito, nas fronteiras com o mundo não cigano.

Evidencia-se, portanto, a resistência de uma minoria que almeja ser reconhecida e ter garantias de seus direitos como categoria social, legitimando as suas demandas em respeito às suas especificidades étnico-culturais (por exemplo: Lima, 2014; Seppir, 2013a;b). Contudo, somente estratégias de sobrevivência e de adaptação de indivíduos e/ou pequenos grupos de ciganos, não são suficientes para mudar o panorama de invisibilidade e de exclusão social dos ciganos no Brasil (Moonen, 2013). Diante dessa realidade social, os avanços científicos em pesquisas e estratégias de atuação profissional junto aos ciganos se fazem cada vez mais necessários, principalmente para a produção de conhecimento e a promoção de políticas públicas realísticas e condizentes às necessidades da população cigana (Cittadini, 2018; Lima, 2014; Moonen, 2013).

A Psicologia, como ciência e profissão, em suas diferentes frentes de atuação, pode fornecer importantes contribuições à questão cigana em território nacional. Experiências já realizadas em outros contextos nacionais sinalizam que os/as psicólogos/as podem atuar na questão cigana: em áreas relacionadas à comunicação eficaz entre ciganos e não ciganos; no engajamento das crianças, dos jovens e das famílias ciganas nos serviços de educação, saúde e assistência social; em programas de treinamento e desenvolvimento de diferentes capacidades formativas entre membros das comunidades ciganas; no apoio em momentos de transição dos grupos nômades; na promoção de bem-estar e de saúde mental entre os ciganos; no atendimento psicoterápico mais sensível culturalmente às necessidades da pessoa atendida; no compartilhamento de informações relevantes aos grupos; em situações relacionadas à identidade cigana e aos conflitos identitários; em habilidade de resiliência e mobilidade social; entre outras possibilidades de atuação (Durst, \& Nyírő, 2018; Fundación Secretariado Gitano, 2007; Heaslip, \& Smith, 2016; Robinson, \& Martim, 2008).

No Brasil, diante da limitação tanto de conhecimento sobre os ciganos livre das modulações do senso comum (carregado de estereótipos negativos e crendices sobre o grupo, os quais reforçam o preconceito e a discriminação social) quanto de atuação junto às comunidades ciganas em território nacional 
(grande parte em situação de extrema pobreza), maior implicação e mais envolvimento da Psicologia com as pautas ciganas poderia contribuir para a promoção de autonomia dos grupos, desmistificação de construções sociais sobre os ciganos que fomentam medo social, fortalecimento da identidade étnica entre as gerações e apropriação dos diferentes espaços públicos, ainda vistos como universos do além-fronteira por muitos ciganos, frente à marginalização e à exclusão social a que estão cotidianamente submetidos (Moonen, 2013). Como profissionais da Psicologia, a atuação junto à população cigana precisa ser pautada, portanto, no entendimento das garantias de direitos, no exercício ético da profissão e no respeito à diversidade cultural das etnias ciganas, para promoção de ações comprometidas com a transformação social (Botomé, 2010; Machado, \& Calais, 2018; Robinson, \& Martin, 2008).

\section{Considerações finais}

Apesar das possíveis contribuições do presente estudo à ampliação do conhecimento produzido acerca dos ciganos em território nacional, algumas limitações devem ser reconhecidas, visto que os resultados obtidos não podem ser generalizados a outros ciganos, tampouco a outros grupos calon, que podem possuir formas diferentes de entender e viver a cigani- dade, em função dos seus diversos modos de ocupações territoriais e referências socioculturais.

Nessa perspectiva, enfatizamos a relevância de realização de novos estudos que contemplem os grupos ciganos em diferentes espaços de inserção social, fomentando o debate sobre políticas públicas e direitos sociais dos ciganos, tarefa que poderá encontrar na área da Psicologia valiosa contribuição para construção de políticas afirmativas pró-ciganas no país.

Considerando as demandas dos povos ciganos no Brasil (Seppir, 2013a;b), há que se considerar, ainda, que os ciganos e ciganas precisam ter sua inserção promovida e fortalecida também nas diferentes políticas públicas já existentes (como na área da saúde, assistência social, educação, entre outras), que contam com profissionais da Psicologia que podem contribuir nessa tarefa. Em consonância com essa reflexão, reitera-se a necessidade de ampliação do debate e problematização também sobre os efeitos da especificidade no jogo da garantia de direitos: se por um lado podem contribuir para a afirmação de práticas sensíveis a identidades dos grupos minoritários, também podem servir para justificar práticas que segregam os grupos do funcionamento comum das diferentes políticas e espaços públicos, reforçando práticas discriminatórias e zonas de exclusão social.

\section{Referências}

Abrantes, P. (2011). Para uma teoria da socialização. Sociologia: Revista da Faculdade de Letras da Universidade do Porto, 21(1), 121-139.

Abubakar, A., \& Dimitrova, R. (2016). Social connectedness, life satisfaction and school engagement: Moderating role of ethnic minority status on resilience processes of Roma youth. European Journal of Developmental Psychology, 1(1), 1-16. https://doi.org/10.1080/17405629.2016.1161507

Acton, T. (2018). Alternatives to romani identity politics. Ethnic and Racial Studies, 41(13), 2329-2336. https://doi. $\operatorname{org} / 10.1080 / 01419870.2018 .1487570$

Alexandre, J. D., Monteiro, M. B., \& Waldzus, S. (2007). More than comparing with majorities: The importance of alternative comparisons between children from different minority groups. International Journal of Psychology and Psychological Therapy, 7(2), 201-212.

Anoli, L. (2004). Psicologia della cultura. Bologna: Il Mulino.

Azevedo, L. S., \& Cardoso, M. C. (2012). Vida de criança cigana: O brincar no seu processo de escolarização. Saberes em Perspectiva, 2(4), 13-27.

Bardin, L. (2010). Análise de conteúdo. Lisboa: 70. (Trabalho original publicado em 1977).

Batista, M. L. C. (2001). Sob o signo da diferença: Histórias e memórias autobiográficas (Dissertação de mestrado). Instituto Superior de Psicologia Aplicada, Lisboa, Portugal.

Berthier, J. (1979). The socialization of the gypsy child. International Social Science Journal, 31(3), 376-392. 
Bigazzi, S., \& Csertő, I. (2016). Minority identity strategies bound by prejudice: Restricted perspectives of people categorized as gypsies in Hungary. Journal of Community \& Applied Social Psychology, 26(3), 189-206. https://doi.org/10.1002/casp.2241

Bonomo, M., Souza, L., Brasil, J. A., Livramento, A. M., \& Canal, F. D. (2010). Gadjés em tendas Calons: Um estudo exploratório com grupos ciganos semi-nômades em território capixaba. Pesquisas e Práticas Psicossociais, 4(2), 160-171.

Bonomo, M., Souza, L., Livramento, A. M., Brasil, J. A., \& Sousa, Y. S. O. (2018). Desenvolvimento humano e cultura cigana: Discutindo a construção e organização de etapas da vida. In: E. Rosa, C. R. R. Nascimento, \& D. B. Nascimento (Orgs.), Jovens e adolescentes: Contextos e vivências no Espírito Santo (pp. 44-57).Vitória, ES: GM.

Botomé, S. P. (2010). A quem nós, psicólogos, servimos de fato? In: O. H. Yamamoto, \& A. L. F. Costa (Orgs.), Escritos sobre a profissão de psicólogo no Brasil (pp. 171-203). Natal, RN: Universidade Federal do Rio Grande do Norte.

Carvalho, L. M. C. R. (2005). Identidade étnica e estratégias de aculturação em contextos multiculturais: Estudos com crianças e agentes socializadores (Tese de doutorado). Instituto Superior de Ciências do Trabalho e da Empresa, Lisboa, Portugal.

Casa-Nova, M. J. (2005). Etnicidade e educação familiar. Revista Teoria e Prática da Educação, 8(2), 207-214.

Castro, D. S. (2011). O olhar de si e o olhar dos outros: Um itinerário através das tradições e da identidade cigana. (Dissertação de mestrado). Universidade Católica do Rio Grande do Sul, Porto Alegre, RS, Brasil.

Castro, T. G., Abs, D., \& Sarriera, J. C. (2011). Análise de conteúdo em pesquisas de psicologia. Psicologia: Ciência e Profissão, 31(4), 814-825. https://doi.org/10.1590/S1414-98932011000400011

Cittadini, S. (2018). Roma, adequate housing, and the home: Construction and impact of a narrative in EU policy documents. Critical Romani Studies, 1(2), 40-56. https://doi.org/10.29098/crs.vli2.4

Condon, L., Bedford, H., Ireland, L., Kerr, S., Mytton, J., Richardson, Z. et al. (2019). Engaging gypsy, Roma, and traveller communities in research: Maximizing opportunities and overcoming challenges. Qualitative Health Research, 29(9), 1324-1333. https://doi.org/10.1177/1049732318813558

Costa, C. V. F. (2015). Ciganas em movimento: Um estudo sobre a autonomia e emancipação social de mulheres calins e suas práticas nômades no interior do Rio de Janeiro (Tese de doutorado). Universidade Federal do Rio de Janeiro, Rio de Janeiro, RJ.

Čvorović, J. (2005). Gypsy ethnic socialization in Serbia. Glasnik Etnografskog Instituta SANU, (53), 35-48. https://doi.org/10.2298/GEI0553035C

Demartis, L. (1999). Compendio de sociologia. Lisboa: Edições 70.

Dias, L. V. (2016). Dança cigana, inclusão social e subjetividade (Dissertação de mestrado). Universidade Católica de Brasília, Brasília, DF.

Dimitrova R., \& Ferrer-Wreder L. (2017). Positive youth development of Roma ethnic minority across Europe. In: N. Cabrera, \& B. Leyendecker (Eds.), Handbook on positive development of minority children and youth (pp. 1-32). Cham: Springer.

Dimitrova, R., Ferrer-Wreder, L., \& Trost, K. (2015). Intergenerational transmission of ethnic identity and life satisfaction of Roma minority adolescents and their parents. Journal of Adolescence, 45(1), 296-306. https://doi. org/10.1016/j.adolescence.2015.10.014

Dimitrova, R., Johnson, D. J., \& Van de Vijver, F. J. R. (2018). Ethnic socialization, ethnic identity, life satisfaction and school achievement of Roma ethnic minority youth. Journal of Adolescence, 62(1), 175-183. https://doi. org/10.1016/j.adolescence.2017.06.003

Durst, J., \& Nyírő, Z. (2018). Soul work and giving back: Ethnic support groups and the hidden costs of social mobility: Lessons from hungarian Roma graduates. East European Journal Of Society And Politics, 4(1), 88-108. https://doi.org/10.17356/ieejsp.v4il.406

Elkin, F. (1968). A criança e a sociedade. Rio de Janeiro, RJ: Bloch.

Emiliani, F. (2008). La realtà delle piccole cose: Psicologia del quotidiano. Bologna: Il Mulino.

Ferrari, F., \& Fotta, M. (2014). Brazilian gypsiology: A view from anthropology. Romani Studies, 24(2), 111-136. https://doi.org/10.3828/rs.2014.6 
Flick, U. (2009). Desenho da pesquisa qualitativa. Porto Alegre, RS: Artmed.

França, D. X. (2013). A socialização e as relações interétnicas. In: L. Camino, A. R. R. Torres, M. E. O. Lima, \& M. E. Pereira (Orgs.), Psicologia social: Temas e teorias (pp. 541-587). Brasília, DF: Technopolitik.

Fundación Secretariado Gitano. (2007). Comunità ROM e salute in Italia. Madri: o autor. Recuperado de http:// ec.europa.eu/health/ph_projects/2004/action3/docs/2004_3_01_manuals_it.pdf

Garrido, A. (1999). Entre Gitanos e Payos: Relación de prejuícios y desacuerdos. Barcelona: Flor Del Viento.

Grigorowitschs, T. (2008). O conceito "socialização" caiu em desuso? Uma análise dos processos de socialização na infância com base em Georg Simmel e George H. Mead. Educação \& Sociedade, 29(102), 33-54. https://doi. org/10.1590/S0101-73302008000100003

Heaslip, V., \& Smith, S. (2016). Working with people from diverse cultures: Cultural competence, a knowledge domain, or a way of being? International Journal of Therapy And Rehabilitation, 23(11), 553-554. https://doi. org/10.12968/ijtr.2016.23.11.553

Hogg, M. A., Abrams, D., \& Brewer, M. B. (2017). Social identity: The role of self in group processes and intergroup relations. Group Processes \& Intergroup Relations, 20(5), 570-581. https://doi.org/10.1177/1368430217690909

Hughes, D., Rodriguez, J., Smith, E. P., Johnson, D. J., Stevenson, H. C., \& Sicer, P. (2006). Parents' ethnic-racial socialization practices: A review of research and directions for future study. Developmental Psychology by the American Psychological Association, 42(5), 747-770. https://doi.org/10.1037/0012-1649.42.5.747

Hutchison, P., Chihade, R., \& Puiu, A. A. (2018). Predictors of "the last acceptable racism": Group threats and public attitudes toward gypsies and travellers. Journal of Applied Social Psychology, 48(5), 237-247. https://doi. org/10.1111/jasp.12508

Kende, A., Hadaricsa, M., \& Lášticováb, B. (2017). Anti-Roma attitudes as expressions of dominant social norms in Eastern Europe. International Journal of Intercultural Relations, 60(1), 12-27. https://doi.org/10.1016/j.ijintrel.2017.06.002

Lalueza, J. L., \& Crespo, I. (2009). Voices in the "gypsy developmental project”. Mind, Culture, and Activity, 16(3), 263-280. https://doi.org/10.1080/10749030802601304

Law, I., \& Kovats, M. (2018). Rethinking Roma, mappings global racisms. Basingstoke: MacMillan.

Levinson, M. P. (2005). The role of play in the formation and maintenance of cultural identity: Gypsy children in home and school contexts. Journal of Contemporary Ethnographm, 34(5), 499-532. https://doi. org/10.1177/0891241605279018

Levinson, M. P. (2008). Not just content, but style: Gypsy children traversing boundaries. Research in Comparative and International Education, 3(3), 235-249. https://doi.org/10.2304/rcie.2008.3.3.235

Lima, M. E. O., Faro, A., \& Santos, M. R. (2016). A desumanização presente nos estereótipos de índios e ciganos. Psicologia: Teoria e Pesquisa, 32(1), 219-228. https://doi.org/10.1590/0102-37722016012053219228

Lima, T. R. S. (2014). Ciganos: Breve definição e análise dos movimentos sociais e políticas públicas no Brasil até 2014. Humanidades em Diálogo, 6(1), 225-237. https://doi.org/10.11606/issn.1982-7547.hd.2014.106271

Machado, C. B., \& Calais, L. B. (2018). Entrelaçando (im)possibilidades: Reflexões sobre a atuação da psicologia social comunitária na atenção primária à saúde. Pesquisas e Práticas Psicossociais, 13(4), 1-15.

Magano, O. (2010). Tracejar vidas normais: Estudo qualitativo sobre a integração social de indivíduos de origem cigana na sociedade portuguesa (Tese de doutorado). Universidade Aberta, Lisboa, Portugal.

Magano, O. (2017). Tracing normal lives: Between stigma and the will to be cigano. Social Identities, 23(1), 44-55. https:// doi.org/10.1080/13504630.2016.1227700

Messing, V. (2019). Conceptual and methodological considerations in researching "Roma migration". In: T. Magazzini, \& S. Piemontese (Eds.), Constructing Roma migrants (Imiscoe research series, pp. 17-30). Cham: Spring.

Miškolci, J., Kováčová, L., \& Rigová, E. (2018). Countering hate speech on Facebook: The case of the roma minority in Slovakia. Social Science Computer Review. https://doi.org/10.1177/0894439318791786

Monteiro, E. N. J., \& Goldfarb, M. P. L. (2017). A infância Calon: Notas sobre o "ser criança" entre os ciganos no Vale do Mamanguape - Paraíba/Brasil. Fragmentos de Cultura, 27(1), 19-29. https://doi.org/10.18224/frag.v27i1.5445 
Montenegro, M. (2013). Aprender a ser cigano hoje: Empurrando e puxando fronteiras. In: O. Magano, \& M. M. Mendes (Orgs.), Ciganos portugueses: Olhares cruzados e interdisciplinares em torno de políticas sociais e projectos de intervenção social e cultural (pp. 9-29). Lisboa: Centro de Estudos das Migrações e das Relações Interculturais.

Montini, P. M. (2017). O período de transição entre a infância e a vida adulta dos ciganos Calon: Considerações sobre a adolescência. (Dissertação de mestrado). Universidade de São Paulo, São Paulo, SP.

Moonen, F. (2012). Anticiganismo: Os ciganos na Europa e no Brasil. Recife, PE: Núcleo de Estudos Cigano.

Moonen, F. (2013). Políticas ciganas no Brasil e na Europa: Subsídios para encontros e congressos ciganos no Brasil. Recife, PE: Núcleo de Estudos Cigano.

Natividade, M. R., Coutinho, M. C., \& Zanella, A. V. (2008). Desenho na pesquisa com crianças: Análise na perspectiva histórico-cultural. Contextos Clínicos, 1(1), 9-18.

Nelson, S. C., Syed, M., Tran, A. G. T. T., Hu, A. W., \& Lee, R. M. (2018). Pathways to ethnic-racial identity development and psychological adjustment: The differential associations of cultural socialization by parents and peers. Developmental Psychology, 54(11), 2166-2180. https://doi.org/10.1037/dev0000597

Nesdale, D. (2001). Language and the development of children's ethnic prejudice. Journal of Language and Social Psychology, 20(1-2), 90-110. https://doi.org/10.1177/0261927X01020001005

Oliveira, D. C. (2008). Análise de conteúdo temático-categorial: Uma proposta de sistematização. Revista de enfermagem UERJ, 16(4), 569-576.

Ollaik, L. G., \& Ziller, H. M. (2012). Concepções de validade em pesquisas qualitativas. Educação e Pesquisa, 38(1), 229-242. https://doi.org/10.1590/S1517-97022012005000002

Ozkan, A. R. (2006). Marriage among the gypsies of Turkey. The Social Science Journal, 43(3), 461-470. https://doi. org/10.1016/j.soscij.2006.04.003

Paiva, M. M. (2013). Aprender a ser cigano, hoje: Empurrando e puxando fronteiras (Tese de doutorado). Universidade de Lisboa, Lisboa, Portugal.

Pinheiro, A. L. A. (2012). Os ciganos de carrazeda de ansiães: Estudo sobre a percepção da situação social (Dissertação de mestrado). Universidade Fernando Pessoa, Porto, Portugal.

Pinto, A. K. P. (2017). Entre andanças, transformações e fronteiras: (Re) significações da escola por ciganos do Espírito Santo (Tese de doutorado). Universidade Federal do Espírito Santo, Vitória, ES.

Pizzinato, A. (2009). Identidade narrativa: Papéis familiares e de gênero na perspectiva de meninas cigana. Arquivos Brasileiros de Psicologia, 61(1),38-48.

Pnevmatikos, D., Geka, M., \& Divane, M. (2010). The emergence, structure and development of ethnic identity during childhood: The case of Roma identity. International Journal of Psychology, 45(6), 435-442. https://doi.org /10.1080/00207594.2010.491120

Poveda, D., \& Marcos, T. (2005). The social organization of a 'stone fight': Gitano children's intrepretive reproduction of ethnic conflict. Childhood, 12(3), 327-349. https:// doi.org/10.1177/0907568205049889

Powell, R. (2008). Understanding the stigmatization of gypsies: Power and the dialectics of (dis)identification. Housing, Teory and Society, 25(2), 87-109. https://doi.org/10.1080/14036090701657462

Powell, R., \& Lever, J. (2017). Europe's perennial 'outsiders': A processual approach to Roma stigmatization and ghettoization. Current Sociology, 65(5), 680-699. https://doi.org/10.1177/0011392115594213

Robinson, M., \& Martin, K. (2008). Approaches to working with children, young people and families for traveller, irish traveller, gypsy, Roma and show people communities: A literature review report for the children's workforce development council. Slough: National Foundation for Educational Research. Recuperado de https://eric.ed.go$\mathrm{v} /$ ?id=ED501860

Rodriguez, S. (2011). Gitanidad: Outra manera de ver el mundo. Barcelona: Kaírós.

Rosário, P., Núñez, J. C., Vallejo, G., Azevedo, R., Pereira, R. et al. (2017). Promoting gypsy children's behavioural engagement and school success: Evidence from a four-wave longitudinal study. British Educational Research Journal, 43(3), 554-571. https://doi.org/10.1002/berj.3271 
Secretaria de Políticas de Promoção da Igualdade Racial - Seppir. (2013a). Guia de políticas públicas para povos ciganos. Brasília, DF: o autor. Recuperado de http://www.seppir.gov.br/portal-antigo/.arquivos/guia-de-politicas-publicas-para-povos-ciganos/view (era Brasil.)

Secretaria de Políticas de Promoção da Igualdade Racial - Seppir. (2013b). Relatório executivo. Trabalho apresentado na Semana Nacional dos Povos Ciganos, Brasília, DF, 1. Recuperado de http://www.seppir.gov.br/comunidades-tradicionais/relatorio-executivo-brasil-cigano.pdf (era Brasil.)

Silva, F. J. O., \& Paiva, M. M. (2015). Romanesthàn go to school: Educational experiences with children gypsy. Tópicos Educacionais, 21(1), 166-188.

Simões, S. R. (2010). Educação cigana: Entre-lugares entre escola e comunidade étnica. REP: Revista Espaço Pedagógico, 17(2), 348-355. https://doi.org/10.5335/rep.2013.2043

Simões, S. R. C. F. (2014). Vida cigana: Aspectos que configuram as atuais dinâmicas das mudanças dos ciganos brasileiros. (Tese de doutorado). Universidade do Sul de Santa Catarina, Palhoça, SC.

Souza, L., Bonomo, M., Livramento, A. M., Brasil, J. A., \& Canal, F. D. (2009). Processos identitários entre gitanos: Desde la exclusión hasta una cultura de libertad. Liberabit, 15(1), 29-37.

Tajfel, H. (1983). Grupos humanos e categorias sociais II. Lisboa: Horizonte.

Tomizaki, K. (2010). Transmitir e herdar: O estudo dos fenômenos educativos em uma perspectiva intergeracional. Educação \& Sociedade, 31(111), 327-346. https:// doi.org/10.1590/s0101-73302010000200003

Tremlett, A. (2017). Visualising everyday ethnicity: Moving beyond stereotypes of Roma minorities. Identities, 24(6), 720-740. https:// doi.org/10.1080/1070289X.2017.1379927

Villano, P., Fontanella, L., Fontanella, S., \& Donato, M. D. (2017). Stereotyping Roma people in Italy: IRT models for ambivalente prejudice measurement. International Journal of Intercultural Relations, 57(1), 30-41. https://doi. org/10.1016/j.ijintrel.2017.01.003

Wallace, C. D., Townsend, L., \& Salemink, K. (2018). Gypsy-traveler communities in the UK and the Netherlands: Socially and digitally excluded? Media, Culture \& Societ.y

Zachos, D. T., \& Panagiotidou, A. (2019). Roma parents' perceptions on education. Journal of Advances in Education Research, 4(1), 13-23. https://doi.org/10.22606/jaer.2019.41002

\section{Grecy Kelle Andrade Cardoso}

Doutoranda em Psicologia pelo Programa de Pós-Graduação em Psicologia ela Universidade Federal do Espírito Santo (UFES), Vitória - ES. Brasil. Mestre em Psicologia pela UFES.

E-mail: grecy.kelle@gmail.com

https://orcid.org/0000-0002-6384-3545

\section{Mariana Bonomo}

Professora do Departamento de Psicologia Social e do Desenvolvimento e do Programa de Pós-Graduação em Psicologia da Universidade Federal do Espírito Santo (UFES), Vitória - ES. Brasil. Doutora em Psicologia pela UFES.

E-mail: marianadalbo@gmail.com

https://orcid.org/0000-0002-3919-3976

Endereços para correspondência:

Programa de Pós-Graduação em Psicologia. Centro de Ciências Humanas e Naturais, Universidade Federal do Espírito Santo.

Recebido 12/04/2019

Aceito 06/05/2019 
Psicologia: Ciência e Profissão 2019 v. 39 (n.spe), e222651, 67-84.

Received 04/12/2019

Approved 05/06/2019

Recibido 12/04/2019

Aceptado 06/05/2019

Como citar: Cardoso, G. K. A., \& Bonomo, M. (2019). Infância Calin: Socialização étnica e identidade social entre crianças ciganas. Psicologia: Ciência e Profissão, 39(n.spe), 67-84. https://doi.org/10.1590/1982-3703003222651

How to cite: Cardoso, G. K. A., \& Bonomo, M. (2019). Calin childhood: Ethnic socialization and social identity among gypsy children. Psicologia: Ciência e Profissão, 39(n.spe), 67-84. https://doi.org/10.1590/1982-3703003222651

Cómo citar: Cardoso, G. K. A., \& Bonomo, M. (2019). Infancia Calín: Socialización étnica e identidad social entre niños gitanos. Psicologia: Ciência e Profissão, 39(n.spe), 67-84. https:// doi.org/10.1590/1982-3703003222651 